\title{
The Strain Amplification Sensor: A 3D-Printable Stand-alone Strain Gauge for Low-Cost Monitoring
}

\author{
Mark Groden $^{\mathrm{a}}$, Kaihua Zhang ${ }^{\mathrm{b}}$, Matt Collette ${ }^{\mathrm{c}}$ \\ ${ }^{a}$ Department of Naval Architecture and Marine Engineering, University of Michigan, \\ Ann Arbor, MI \\ ${ }^{b}$ Department of Naval Architecture and Marine Engineering, University of Michigan, \\ Ann Arbor, MI \\ ${ }^{c}$ Department of Naval Architecture and Marine Engineering, University of Michigan, \\ Ann Arbor, MI
}

\begin{abstract}
Current in-situ strain sensing techniques focus on determining accurate, time-histories of strain utilizing fairly complex sensing, compensation, data processing, and powering arrangements. A simpler and lower-cost strain sensing approach would open up more opportunities to use strain measurements to support engineering decision making. This work explores a fully mechanical, ultra-low cost strain sensor printed using additive manufacturing techniques. The accuracy of current additive manufacturing techniques are discussed, and the performance of the sensor in terms of accuracy, measurement repeatability, and batch-to-batch manufacturing variability are studied. An example of using the proposed sensor to measure transient thermal weld stresses is presented. Overall, the key challenge to such a sensor is shown to be the accuracy of pin and slot print features and the resulting slip and friction introduced into the sensor. A properly calibrated design printed with current state-of-the-art machines is shown to be capable of resolving strain changes on the order of one micro strain with good repeatability.
\end{abstract}

Keywords: Strain Gauge, Additive manufacturing, 3D printing, Structural Reliability, Weld Distortion

\section{Introduction}

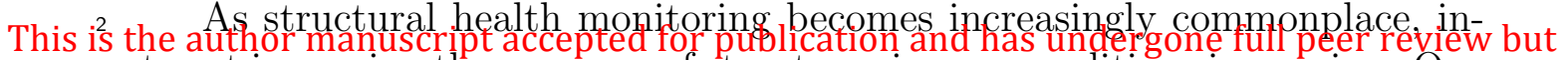
3 terest in sensing the response of structures in new conditions is growing. One has not been through the copyediting, typesetting, pagination and proofreading process, which may lead to differences between this version and the Version of Record. Please cite this article as doi: 18 .

November 13, 2017 
challenge for current sensing systems is very short-term monitoring. If the monitoring window is only a few hours or days long, then the set-up overhead for conventional strain-measuring systems significantly impacts their practicality. In certain applications, such as post-damage event support on oceangoing vessels or offshore oil installations, having sensors that are intrinsically safe in explosive atmospheres is an additional challenge. This work proposes and tests a fully mechanical, ultra-low cost strain sensor printed using additive manufacturing, or 3-D printing, techniques. In many ways this sensor is a simpler variant of a laboratory extensometers produced at the fraction of a cost of a laboratory device. It provides instantaneous indication of current strain directly in human-readable form. The objective of such a device is short-term strain sensing problems where understanding the current strain state is more important than obtaining a complete time history. Examples of such uses include measuring welding-induced thermal stresses during construction, or rapidly instrumenting a structure after a damage event to understand strains local to the damage. This work discusses the development of this gauge, and the current limitations of additive manufacturing for this type of device.

The ability to sense structural responses has dramatically expanded in the past two decades. Conventional strain gauges, fiber optic, capacitive sensors and active sensing techniques have all been proposed. For example, Lim[1] has shown that distributed fiber optic sensors are promising when used to monitor the cross section deformation of pipes. S. Laflamme [2] designed a soft capacitive sensor to localize damage on large civil structures which measures strain induced capacitance change. Remote wind turbine blade monitoring [3] demonstrated that wired conventional strain gauges could aid in damage detection. Today a wide variety of sensor technologies exist, however, the majority of the research focus to date has been on improving sensor capabilities, not on reducing sensor cost.

Discussion on cost reduction has focused on two primary avenues to date. The first is to minimize the installation costs by switching from a wired system to a wireless sensing system. On shipboard applications, running wires through watertight compartments is difficult and expensive. Even for bridges wired systems are expensive to implement [4]. Wireless systems can significantly reduce these costs, so long as a means of providing energy to the sensors is possible [5]. H. Choi [6] proposed a cost effective wireless transmission that uses multi-hop data transmission between nodes to mitigate the energy used in transmitting data. Extracting energy from the struc- 
ture has also been explored, for example [7] proposed a vibration harvesting method for long term monitoring of bridges. For short-term applications, battery powered systems have been proposed. Lynch et al. demonstrated a battery-powered wireless system that could be rapidly installed for strain and acceleration monitoring on a small patrol boat [8].

The second approach to reducing cost is to simplify the installation of strain gauges on the structure. By pre-configuring, wiring, and packaging the gauges into a compact unit that only needs to be attached to the structure by simple lugs or bolts installation time is reduced. Such quick-attaching strain sensors are made by BDI for bridge sensors [9] or bolt-on strain sensors for silo weight estimates reduce installation time by removing surface preparation, mounting, and temperature-compensation, and bridge wiring for the strain gauges. Both wireless and quick-attaching strain systems reduce the cost of installing a full monitoring system. However, such systems still require electrical power, signal conditioning, and data acquisition systems to determine and display strain values. For short-term monitoring (hours to days) of the current strain in a handful of locations, could a more rapid and simpler solution be imagined?

Recent advances in additive manufacturing, or 3D printing, technology have enabled construction with increasing repeatability and accuracy [10] [11]. These developments are predicted to extend the utility of additive manufacturing from rapid prototyping to production-scale fabrication. Of the various additive manufacturing techniques available today such as direct deposition and laser sintered powders, the stereolithography technique is noted for its growing ability to produce precise parts. In stereolithography, an ultraviolet light source paints the shape to be fabricated in a vat of photo-polymer resin. When the light strikes the resin, the resin solidifies, and through repeated tracing of slices of the outline of a part, the part slowly emerges from the resin. In the past ten years there have been significant advances in photoinitiated polymerization [12], which have provided stereolithography the highest fabrication accuracy [13]. Recent work [14] has produced 3D monolithic structures with embedded electronics and printed interconnects using stereolithography techonology. With the increasing accuracy of the stereolithography, the possibility of printing a mechanism that could amplify strain to human-readable motion appeared worth exploring. As such a device would be entirely mechanical and plastic, it would not require power sources, data logging or other systems traditionally needed for strain sensing. The low cost of printing such a mechanism would also mean 
that the device could be used in a disposable manner. This combination of low cost and simple installation could allow real-time strain sensing in applications where traditional system struggle to be practical or cost-effective. In this paper, all 3D printed prototypes were produced by the stereolithography process.

A patented stand-alone mechanical strain gauge, the Strain Amplification Sensor (SAS) that optically records strain in real time is presented. First, the design considerations and overview of the development of the 3D-printed manufacturing technique are discussed, followed by sensor calibration, repeatability, manufacturing variability, and a laboratory weld test. In the weld test the SAS is evaluated for its ability to provide real time deformation measurement of transient displacement arising from the thermal input to the weld. Finally, future work extending the SAS technology and conclusions are discussed.

\section{Design}

The SAS is a $3 \mathrm{D}$ printable assembly using only mechanical methods to record strain, figure 1 . The SAS records the average strain between two mounting points in both tension and compression through a sensor arm that activates a series of three amplifying lever arms. Because it is purely mechanical, it could be made intrinsically safe for explosive environments by selecting an appropriate print material. In real time the SAS responds to strain observed on the measurement material and displays the reading on the sensor face. This allows easy, human-readable strain reporting during monitoring without the use of data acquisition system and computers. For fabrication monitoring and incident response, this simplicity is a key advantage.

By being 3D printable, the SAS can easily be tuned to different sensitivities and detection ranges. Present testing is based upon magnetic attachment of the SAS. Magnetic attachment affords the user rapid installation and removal. 3D printing each sensor allows for the tunability with respect to both sensitivity and mounting configuration. The SAS' base can be modified and adapted to the contours of any surface or to mount between two nearby positions on a structure that are not necessarily continuous. The base of the sensor can also be attached more permanently, or to non-magnetic substrates by using any epoxy compatible with the printed plastic. Smaller base sizes would also be possible with epoxy, though the overall length of the device 
is related to the amplification factor of the device, and shrinking the overall size of the device would lead to lower sensitivity.

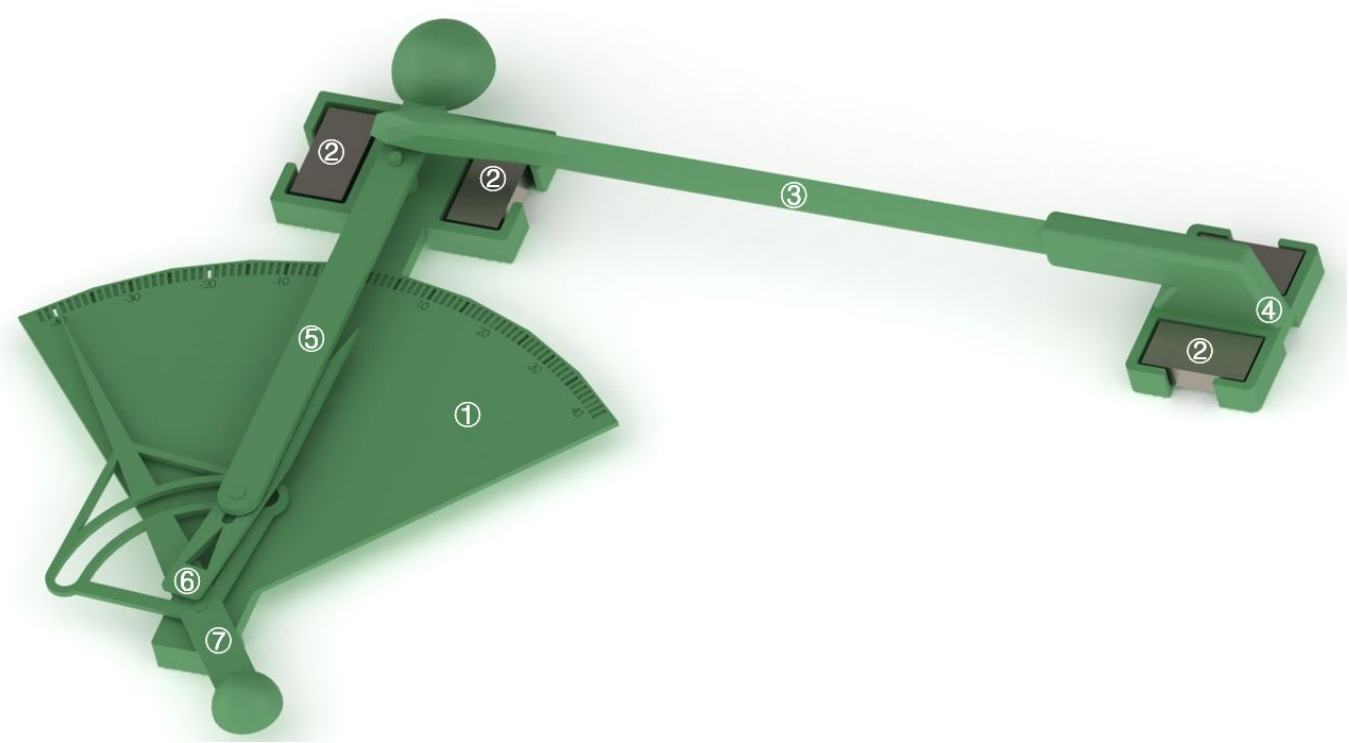

Figure 1: 3D model of SAS (1) Sector Base Plate (2) Magnet (3) Long Sensor Arm (4) Sensor Arm Base Plate (5) Actuator Arm (6) Pointing lever (7) Measurement Pointer)

The principle dimensions of the version of SAS tested are presented in table 1. The sensor arm is designed to span long enough to amplify the strain to a visual displacement on the sensor face, while the base can be modified and adapted to the contour of the surface it is mounted on.

\begin{tabular}{cc}
\hline Length Overall & $123 \mathrm{~mm}$ \\
Width & $84 \mathrm{~mm}$ \\
Height & $14 \mathrm{~mm}$ \\
\hline
\end{tabular}

Table 1: SAS principle dimensions of the version evaluated

SAS operates by measuring the change in displacement between two mounting locations. A rigid, cantilevered beam extends from one side to the other. As the material being measured deforms, the rigid bar places force on the other side of the SAS assembly. This force is translated to motion of a mechanical system and the mechanical reaction divided by the 
known distance over which the cantilevered bar spans produces the basis for strain measurement.

To transform displacement due to strain into a visually observable phenomena, significant amplification of the underlying motion needs to take place. SAS achieves this in two ways. Firstly, for each of its three levers, the fulcrum is placed closer to the lever end on which the excitation is being received, making the opposing end of the lever move over a larger distance proportional to the relative distance between the end points and the fulcrum. Second, the attachment location of the second lever arm to the third and final lever arm induces opposing relative motion between the second lever arm and the third. This interaction further amplifies the motion providing a total theoretical amplification about 2150 of times. Slippage in the joints from imperfect manufacturing reduced this ratio to roughly 1,800 on the actual devices.

As the distance between the two base plates increases or decreases, the lever amplification system is activated. Figure 2 demonstrates the lever system reaction to a decreasing distance between the two base plates. This would correspond to compressive stress in the material being measured. The arrows indicate the moving directions of each individual part. The actuator arm and pointing lever move towards the system while the measurement pointer moves away from system. Oppositely, when the distance between two base plates increases, the actuator arm and pointer move away from the system while measurement pointer moves towards the system.

With 3D printing technology still maturing, much time was spent realizing something close to the CAD models in material form. Resolution capabilities for stereolithography were found to be significantly poorer than those advertised across the industry. In addition, feature accuracy was found to decrease with smaller feature sizes. Stereolithogrpahy prints in layers, which makes printing rounded shapes such as pins and holes somewhat challenging. The majority of the prototyping time was spent iterating through variations on the true dimensions until CAD input dimensions produced parts that were within the required dimensional tolerance.

The limitations of stereolithography primarily impacted the performance of mechanical joints in SAS. SAS uses two mechanical joint types, pin to hole, and pin to slot, as shown in Figure 3. Both connection types require snug but smooth interfaces. If SAS' mechanism generates too much internal stress from friction or interference, it seizes. And failure to transmit motion through connections dramatically reduces the sensitivity and accuracy of the design. 


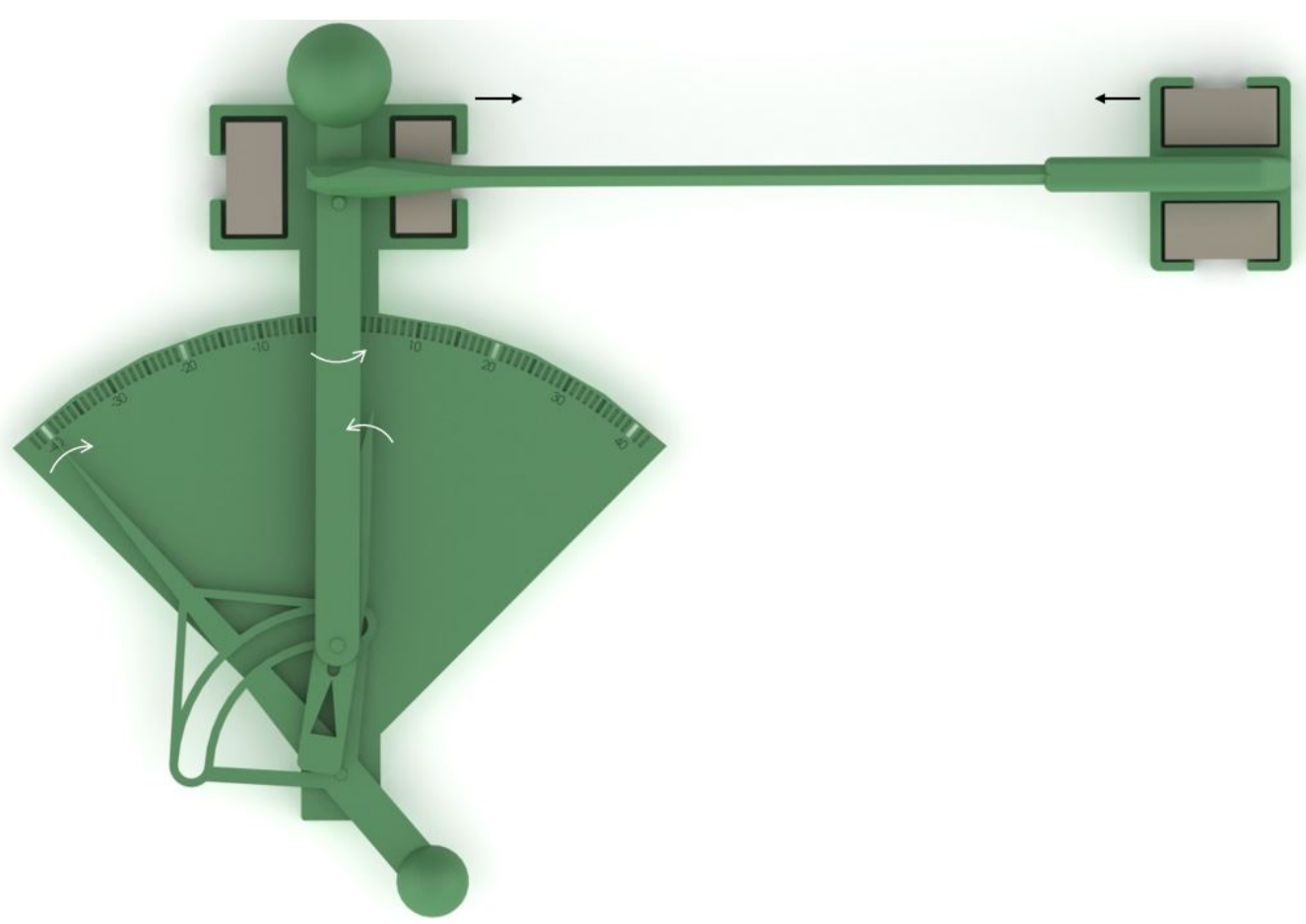

Figure 2: SAS movement illustration, initially in tension and showing movement as compression begins 
Prior to print iteration, SAS was unable to detect a change from tension to compression or vice versa less than $6 \mu \mathrm{m}$; after prototype iteration which mostly focused on optimizing mechanical joints dimensions, this transition gap became $0.4 \mu \mathrm{m}$.
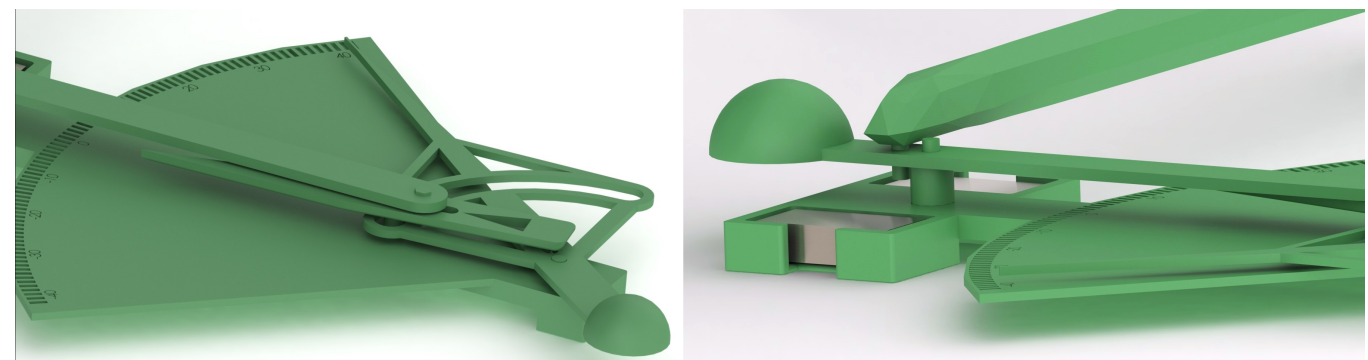

Figure 3: Pin and slot connections and pin and hole connections

It was found that a significant source of error in early designs was caused by the deflection of the long sensor arm under gravity. Deflection occured both along its length and local to the driving pin at its end. Deflection at the end introduced a moment into the pin connection would cause internal stresses in the lever mechanism. To mitigate the deflection, topology optimization was conducted on the sensor arm to reduce its deflection from vertical at the end located by the pin used to drive the lever mechanism. To further reduce internal stresses, each of the levers was balanced about its point of rotation. Balance was accomplished by adding counter weights in the form of half spheres for longer levers and placing lightening holes on the longer side of shorter levers.

\section{Testing and Evaluation}

\subsection{Evaluation of the 3D Printed Assembly}

After several rounds of design iteration, a design and printing approach which produced a workable sensor emerged. However, given the novelty of additive manufacturing for this design, and the range of material choices available for such devices, the repeatability, batch-to-batch variability, and overall performance of the sensor needed to be investigated. A test program spanning more than 30 unique prototypes was used to perform this evaluation. All sensors were manufactured remotely by ProtoLabs, a commercial 3D print company. 3D printing material remains largely non-standardized 
and vendor specific. To characterize the material SAS was manufactured from, the ASTM test results on the material provided by the vendor are provided in Table 2. During the development of the sensor, several print materials were tried. The material differed in the amount of internal friction they would create with identical or similar part designs, however, such properties are not yet standardized. This added to the challenge in developing the prototype gauge. The 3D printer used was the 3D System Viper. The printer's specifications can be seen in Table 3. The cost for 3D printing one set of SAS varied significantly throughout the project, but average near 400 dollars. Much of the variability seemed to be driven by the growing demand for printing dental and medical implants with the same 3D printing technique and machines. At this price point, the device is not yet truly disposable however $3 \mathrm{D}$ printing costs are expected to continue to fall as the technology becomes more established.

\begin{tabular}{|c|c|c|c|}
\hline ASTM Method & Property Description & Metric & English \\
\hline$\overline{\mathrm{D} 638 \mathrm{M}}$ & Tensile Modulus & $2,100 \mathrm{MPa}$ & $305,000 \mathrm{psi}$ \\
\hline D638M & Tensile Strength at Break & $44.9 \mathrm{MPa}$ & $6,500 \mathrm{psi}$ \\
\hline D638M & Elongation to Break & $6.1 \%$ & $6.1 \%$ \\
\hline D790M & Flexural Strength & $74.3 \mathrm{MPa}$ & $10,770 \mathrm{psi}$ \\
\hline D790M & Flexural Modulus & $2,200 \mathrm{MPa}$ & $329,000 \mathrm{psi}$ \\
\hline D2240 & Hardness (Shore D) & 85 & 85 \\
\hline D256A & Izod Impact (Notched) & $0.23 \mathrm{~J} / \mathrm{cm}$ & $0.46 \mathrm{ft} \mathrm{lb} / \mathrm{in}$ \\
\hline D570-98 & Water Absorption & $0.7 \%$ & $0.7 \%$ \\
\hline E831-05 & C.T.E. $-40^{\circ} \mathrm{C}-0^{\circ} \mathrm{C}\left(-40^{\circ} \mathrm{F} \quad 32^{\circ} \mathrm{F}\right)$ & $74.1 \mu \mathrm{m} / \mathrm{m}-{ }^{\circ} \mathrm{C}$ & $41.2 \mu \mathrm{in} / \mathrm{in}-{ }^{\circ} \mathrm{F}$ \\
\hline E831-05 & C.T.E. $0^{\circ} \mathrm{C}-50^{\circ} \mathrm{C}\left(32^{\circ} \mathrm{F} \quad 122^{\circ} \mathrm{F}\right)$ & $96.3 \mu \mathrm{m} / \mathrm{m}-{ }^{\circ} \mathrm{C}$ & $53.6 \mu \mathrm{in} / \mathrm{in}-{ }^{\circ} \mathrm{F}$ \\
\hline E831-05 & C.T.E. $50^{\circ} \mathrm{C}-100^{\circ} \mathrm{C}\left(122^{\circ} \mathrm{F} \quad 212^{\circ} \mathrm{F}\right)$ & $141.8 \mu \mathrm{m} / \mathrm{m}-{ }^{\circ} \mathrm{C}$ & $78.9 \mu \mathrm{in} / \mathrm{in}^{\circ}{ }^{\circ} \mathrm{F}$ \\
\hline E831-05 & C.T.E. $100^{\circ} \mathrm{C}-150^{\circ} \mathrm{C}\left(212^{\circ} \mathrm{F} \quad 302^{\circ} \mathrm{F}\right)$ & $182 \mu \mathrm{m} / \mathrm{m}-{ }^{\circ} \mathrm{C}$ & $101.3 \mu \mathrm{in} / \mathrm{in}-{ }^{\circ} \mathrm{F}$ \\
\hline D150-98 & Dielectric Constant $60 \mathrm{~Hz}$ & 3.16 & 3.16 \\
\hline D150-98 & Dielectric Constant $1 \mathrm{KHz}$ & 3.12 & 3.12 \\
\hline D150-98 & Dielectric Constant $1 \mathrm{MHz}$ & 2.94 & 2.94 \\
\hline D149-97a & Dielectric Strength & $14.89 \mathrm{kV} / \mathrm{mm}$ & $378 \mathrm{~V} / \mathrm{mil}$ \\
\hline E1545-00 & $\operatorname{Tg}$ & $49^{\circ} \mathrm{C}$ & $120^{\circ} \mathrm{F}$ \\
\hline D648 & HDT @ $0.46 \mathrm{MPa}$ (66 psi) & $59^{\circ} \mathrm{C}$ & $138^{\circ} \mathrm{F}$ \\
\hline D648 & HDT @ $1.82 \mathrm{MPa}$ (264 psi) & $50^{\circ} \mathrm{C}$ & $122^{\circ} \mathrm{F}$ \\
\hline
\end{tabular}

Table 2: 3D Print Material Mechanical and Thermal/Electrical Properties (From row1(D638M) to row8(D570-98) are mechanical properties. From row9(E831-05) to row19(D648) are Thermal/Electrical Properties.) 


\begin{tabular}{cccc}
\hline Equipment & Max Build Extents & Layer Thickness & Min Feature Size \\
\hline 3D Systems Viper & $5 " \times 5 " \times 2.5 "$ & $.001 "$ & $.002 "$ \\
\hline
\end{tabular}

Table 3: 3D Printer Technical Specifications

\subsection{Test Apparatuses}

The objectives of the battery of test that were performed included: characterizing the SAS's behavior by determining its response to incrementally increasing strain, which serves as calibration, determining the repeatability of the measurements recorded by SAS and their accuracy, and finally, determining the differences in SAS's performance between different 3D printed batches.

Before testing the entire SAS assembly, the amplification mechanism was isolated and evaluated. Using a P-603 Piezo Movement Actuator from Physik Instrument (PI), material strain displacement was simulated from both tension and compression, Figure 4. This test bed served as the basis for calibration, repeatability testing, and manufacture deviation evaluation between batches.

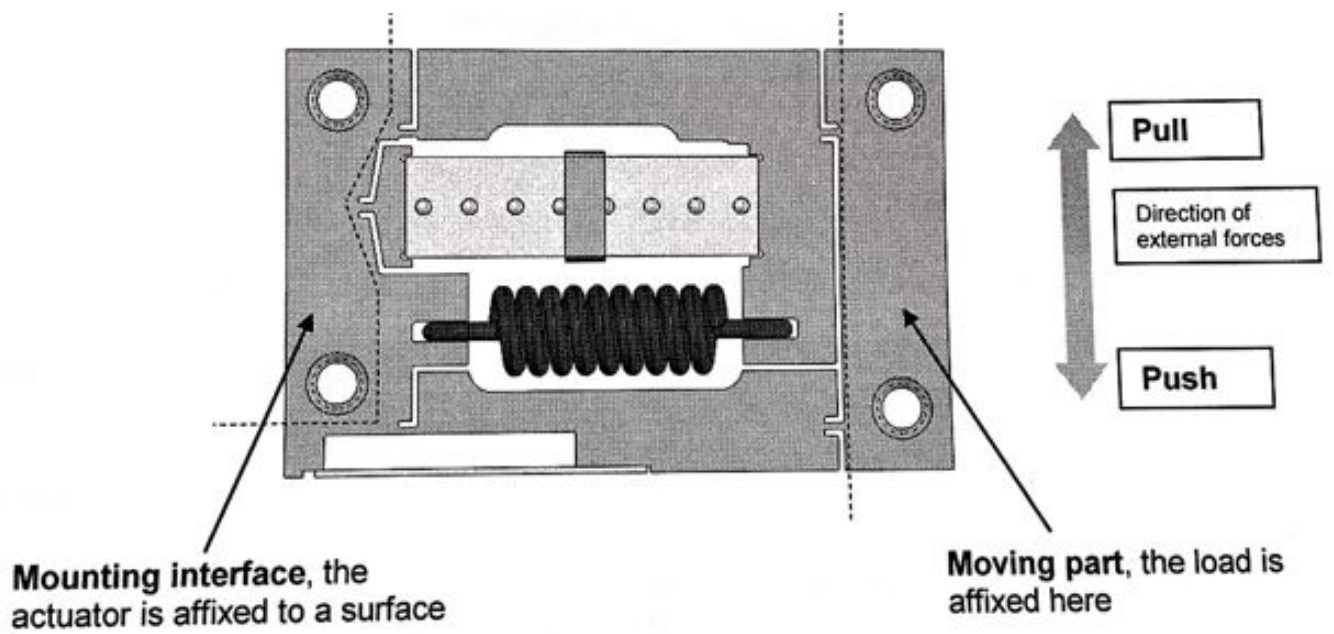

here

Figure 4: Plan View of P-603 Piezo Actuator. 2014. Technical Note of P-603 PiezoMove OEM Flexure-Guided, Lever-Amplified Actuators. Physik Instrument(PI). Germany

From the plan view depicted in Figure 4 of the P-603 piezo actuator, 
the basis for driving SAS can be gathered. Fixing the left screw holes to a surface, the moving part on the right side pulls or pushes the SAS' sensor arm to simulate material tension or compression. An aluminum base plate was used to connect the SAS mechanism to the left side while another aluminum base was used to fix the driving side to a 3D printed driving bar on the right side. Figure 6 shows the SAS mounted. A 3D printed driving bar was chosen as opposed to extending the aluminum base to drive the mechanism to ensure proper simulation of the internal stresses between all joints, including the cantilevered beam.

$L A B V I E W$ was used to activate the piezo motor, through a E-709 Digital Piezo Controller. By commanding "MOV 1 1" or "MVR 1 1" to the write buffer, the piezo actuator can move to a specific position or move continuously with specific step and user-specified repeat time. This served as the basis for command inputs for all the piezo testing.

Figure 5 is the flowchart of the testing process based on piezo actuator. $L A B V I E W$ receives input commands and transfer them to piezo controller which can control piezo actuator's movement. The piezo controller and piezo actuator comprise a feedback system to implement the precise movement requested. A feedback-driven servo is integrated in the digital piezo controller to minimize the error between the command signal and the feedback signal from the position sensor embedded in the motion device.

After evaluating the amplification mechanism alone on the piezo actuator, an assembled SAS was tested on a pull tester. An aluminum test specimen was placed in the jaws of the pull tester device and SAS along with a conventional piezo electric wheatstone bridge strain gauge were place in the center of the specimen, Figure 7. This test set up allowed for testing of the entire SAS mechanism and sensor arm system in tensile stress, and direct comparison to conventional strain testing.

\subsection{SAS Calibration}

To calibrate the SAS, the piezo motor was given commands to move the mechanism at increments on the order of $<1 \mu \mathrm{m}$. Time between each step was varied and the sensor's response to variation in time between induced motion was evaluated.

While testing with several different steps, it was discovered that if the step was too small or too large, SAS would react in an unpredictable manner. That is, for the version of SAS tested, if step sizes were smaller than $0.4 \mu \mathrm{m}$, negligible movement resulted from SAS and over many of such steps, 


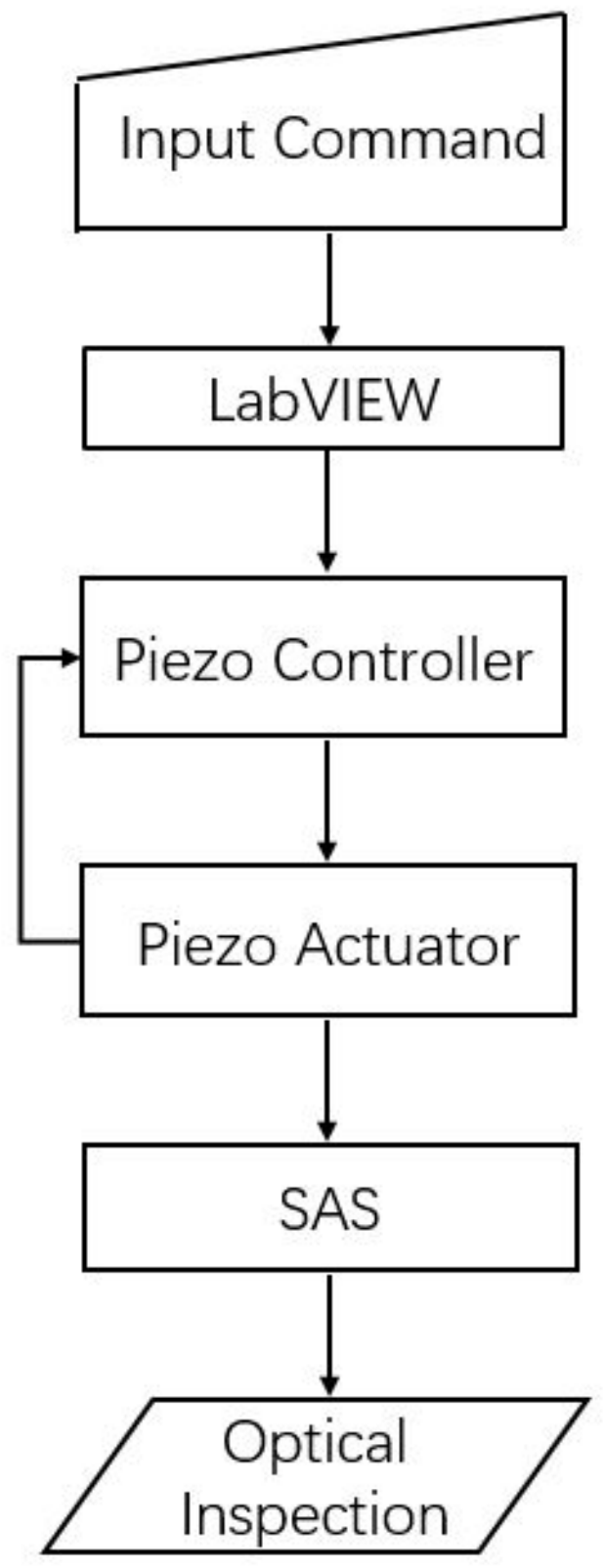

Figure 5: Flowchart for Piezo Actuator Based Test 


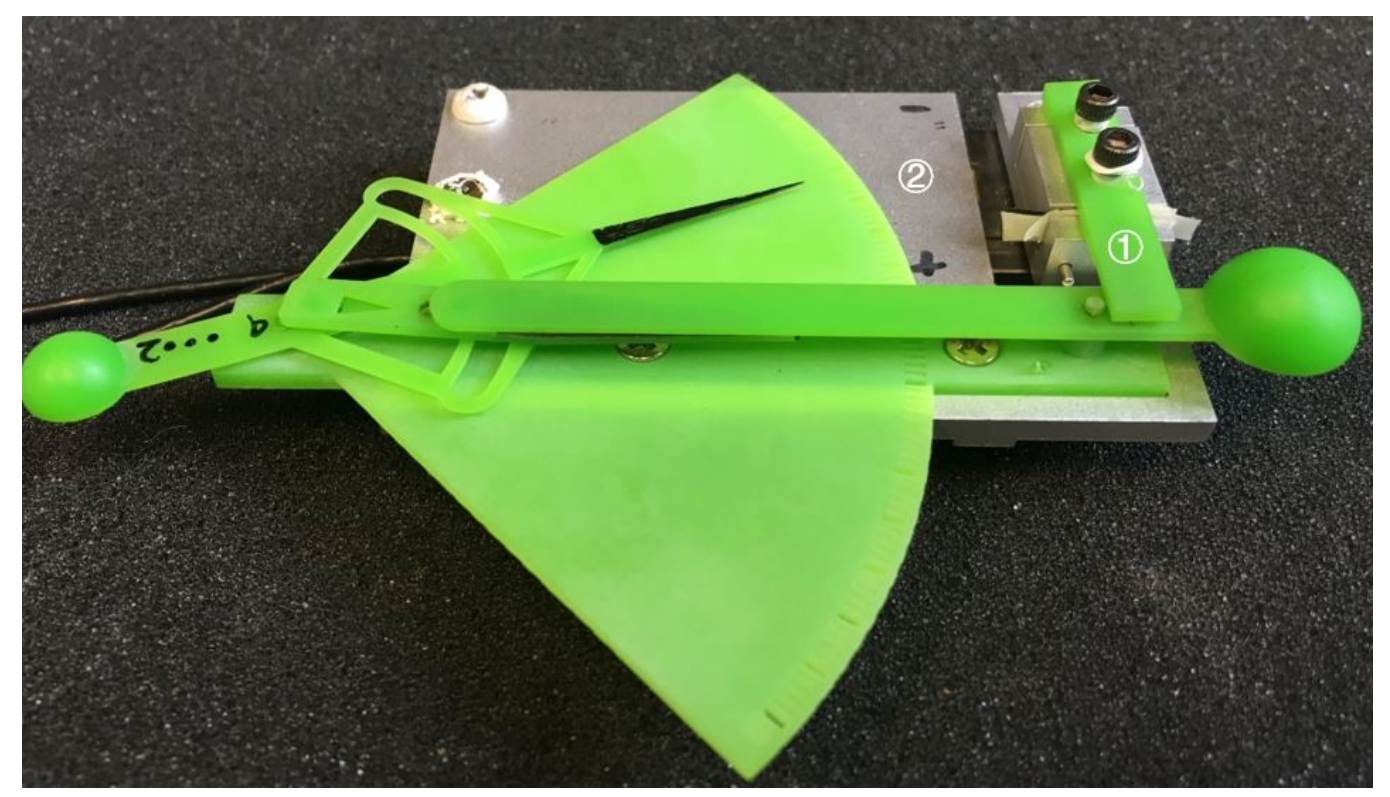

Figure 6: SAS with Aluminum Base on Piezo Actuator (1) Short Sensor Arm (2) Aluminum Base

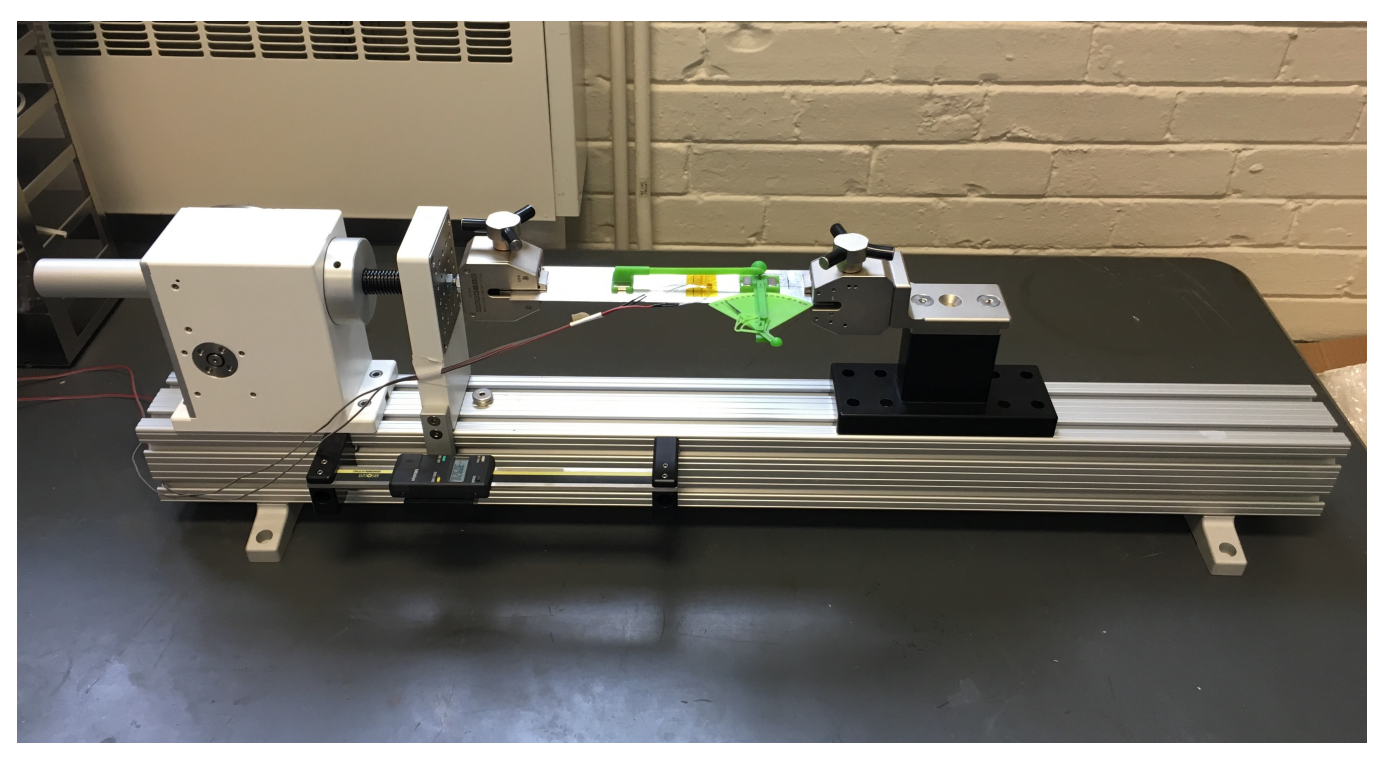

Figure 7: SAS on Pull Tester with Conventional Strain Gauges for Comparison 
significant variability in cumulative motion would result. For this sensor configuration, $0.4 \mu \mathrm{m}$ is less than the minimum detectable movement. Inability to control the rate of motor motion resulted in SAS variability for larger step sizes. The motor motion rate is akin to impulsive loading and not representative of the types of strain the sensor was designed for. For larger steps, $1 \mu \mathrm{m}$ $-2.5 \mu \mathrm{m}$, the high rate of the applied displacement would result in dynamic, not quasi-static response in the gauge. Exposed to this impulse, the SAS would first pass the correct position and rebound back to a reading of lower accuracy. With this in mind, calibration step sizes were evaluated between $0.2 \mu \mathrm{m}$ to $2.5 \mu \mathrm{m}$, with $0.6 \mu \mathrm{m}$ found to be the best step size.

The types of applications envisioned for SAS have slowly-varying loads, with load cycles on the order of several seconds or minutes. Thus, the dynamic response of the gauge was not considered during design. However, SAS is a mechanical system and when operating on a perfectly flat plate and installed with proper alignment it has one degree of freedom: translation of the long sensor arm towards or away from the mechanism side. Therefore there is inherently a natural frequency to the device which is entirely dependent upon the principle dimensions and build material. The rebounding effect and sensitivity described above are specific to the SAS configuration being test. Should SAS be revised for different ranges of sensitivities, rebounding characterization would need to be re-evaluated. When measuring impulsive or dynamic loads with a system like the one proposed here, consideration of the dynamic properties of the gauge is required.

Using $0.6 \mu \mathrm{m}$ as the movement step, five complete passes through tension and compression ranges were conducted, covering $40 \mu \mathrm{m}$ of total displacement. During each step, the pointer rotation angle was recorded. The accuracy of this reading is 0.1 degrees, which can be achieved by visual inspection using markings that were included on the device by the 3D printing process. An increasing slope between pointer angle and displacement is expected when displacement is less than $20 \mu \mathrm{m}$ since from 0 degree to 40 degree internal friction is decreasing. While a decreasing slope is expected when displacement is greater than $20 \mu m$ with inner friction increasing again. Plotting the data and fitting the data with $4^{\text {th }}$ order polynomial function, we acquired the relation between displacement and pointer angle, Figure 8 . Then dividing displacement by sensor arm's length, a relationship between rotation angle and strain is produced. This polynomial provides the basis for measurement of strain using SAS. For an observed pointer angle and known distance between the two sensor bases (or length of the sensor arm) with strain being: 


$$
\eta=\frac{\Delta l}{l}
$$

where $\Delta l$ is the material length change undergoing tension or compression and $l$ is the original length between two SAS base plates, we can solve for the $\Delta l$ given an observed SAS pointer angle reading. The gauge has rotation angles directly printed on the plate beneath the pointer. Once a calibration plot is established for a mechanism design, visual angular readings taken in service can be converted into strain by the plot or the polynomial directly.

The calibration conducted with piezoelectric actuator differs slightly from the use of the gauge with the long sensing arm. Uncertainty in the lever mechanism that increases strain so that it provides a visual reading is the dominant uncertainty in calibration, and is captured with the piezoelectric technique. Errors associated with the magnetic base slipping, or off-center forces from the long arm are not included, however, these are expected to be smaller and are often mounting location dependent. Cross-talk errors from off-axis strain have not yet been characterized. Additionally, some human error from reading the gauge is likely to occur. Under laboratory conditions, the gauge could be read to 0.1 degrees of accuracy. However, errors owing to reading in field conditions, or comparison of readings between different engineers have not yet been characterized.

\subsection{Repeatability}

The repeatability of the results obtained during calibration was examined. Over time, the SAS' mechanical system could be subjected to wear and the measurements could deviate from those at the beginning of its life-cycle. To simulate cyclic deterioration, a total of 50 cyclic stress cycles were induced on the piezo motor test bed. At every $10^{\text {th }}$ cycle the measurement accuracy of SAS was evaluated. Figure 9 displays the measurements from SAS at every $10^{\text {th }}$ cycle. Error regarding each SAS measurement in $i^{\text {th }}$ cycle was calculated by dividing the difference between the SAS measured and input displacements by the input displacements. With displacement increasing, the percentage error tends to decrease and the increase in error comes from SAS' static friction "sticking" which increases error locally. In order to assess error in every $10^{\text {th }}$ cycle, errors associated with each SAS measurement were added up and averaged by total input displacement number. Table 4 shows the average error for $i^{\text {th }}$ cycle. The errors are close indicating that SAS measurement is stable. 


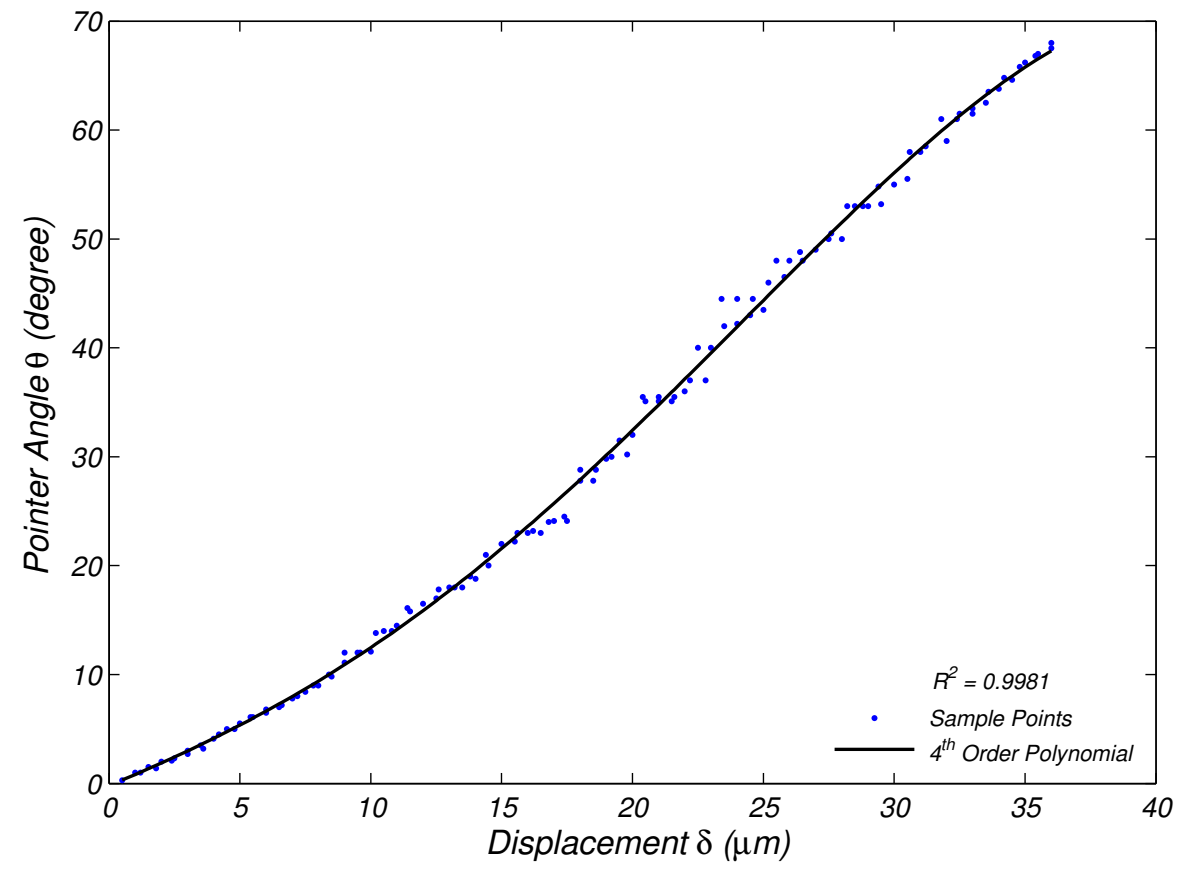

Figure 8: Calibration of the SAS mechanism on the piezo motor at $0.6 \mu \mathrm{m}$ step sizes (Fitting Function: $\theta=-4 E^{-5} \delta^{4}+0.0016 \delta^{3}+0.0138 \delta^{2}+1.0056 \delta-0.1977, R^{2}=0.9981$ ) 
For all of the tests performed below including calibration SAS experienced some sticking in the mechanism's range of movement. Sticking is defined as the mechanism failing to react to a change in input displacement for one increment. This may come from rough edges in pin-hole or pin-slot joints and one displacement increment is not enough to push through a patch of roughness. Thus the error regarding to this input displacement(local error) would increase. Slightly tapping on SAS would help it respond and applying another increment of displacement would also result in a reaction that represents the total input displacement over the past two inputs. This effectively meant SAS would "catch up" and again correctly represent the input displacement. The frequency of the sticking occurrence over all test data points was approximately $5 \%$.

To look at the change in accuracy with changing cycles excluding the sticking effect, as new figure was prepared with the points at which the SAS stuck removed, Figure 10. We can see that all of the 5 cycles' percentage error have similar trends decreasing with increasing displacement. This means the absolute error for each displacement is close which indicates that SAS measurement is stable. The percentage errors after $32 \mu \mathrm{m}$ in $30^{\text {th }}$ cycle and $50^{\text {th }}$ cycle are increasing which is because SAS was stuck in the previous movement and the error is thus increasing.

\begin{tabular}{cccccc}
\hline$i^{\text {th }}$ Cycle & 10 & 20 & 30 & 40 & 50 \\
Average Percentage Error $(\%)$ & 2.75 & 2.97 & 2.81 & 2.86 & 3.10 \\
\hline
\end{tabular}

Table 4: Average Percentage Error

As can be seen in Figure 11, the SAS measurement standard deviation of $i^{\text {th }}$ cycle tends to decrease as the number of cyclic range passes increases. This is likely because there is something of a break-in period for the $3 \mathrm{D}$ printed plastic. Rough edges are smoothed with repeated passes. It is expected that over time the standard deviation will become asymptotic before increasing at some point when the mechanism begins to deteriorate. For short-term monitoring applications however, such results indicate that an acceptable life can be achieved with current additive manufacturing materials.

(The information in Figures 11 and 12 may be better presented as a bar charts or tables) 


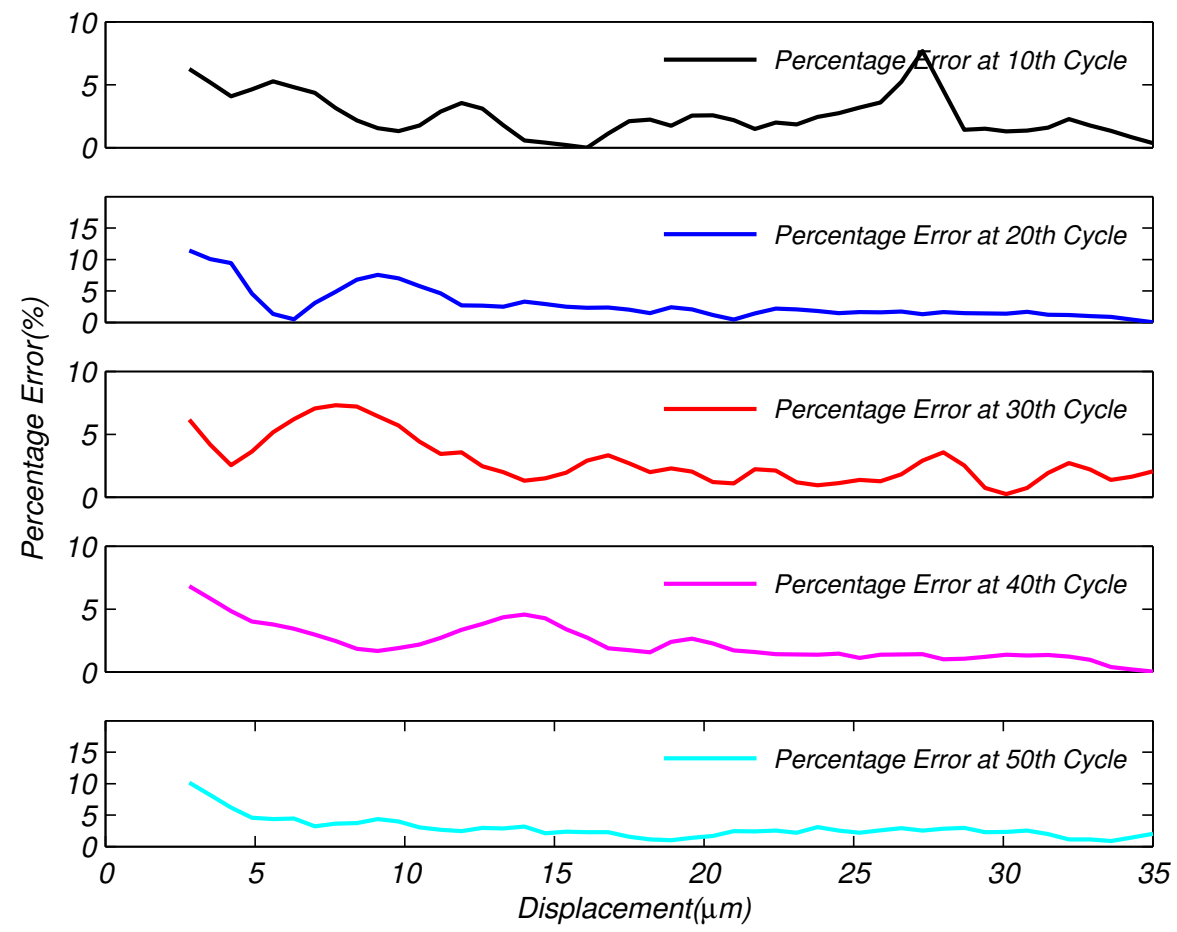

Figure 9: Repeatability test over 50 cycles with all points 


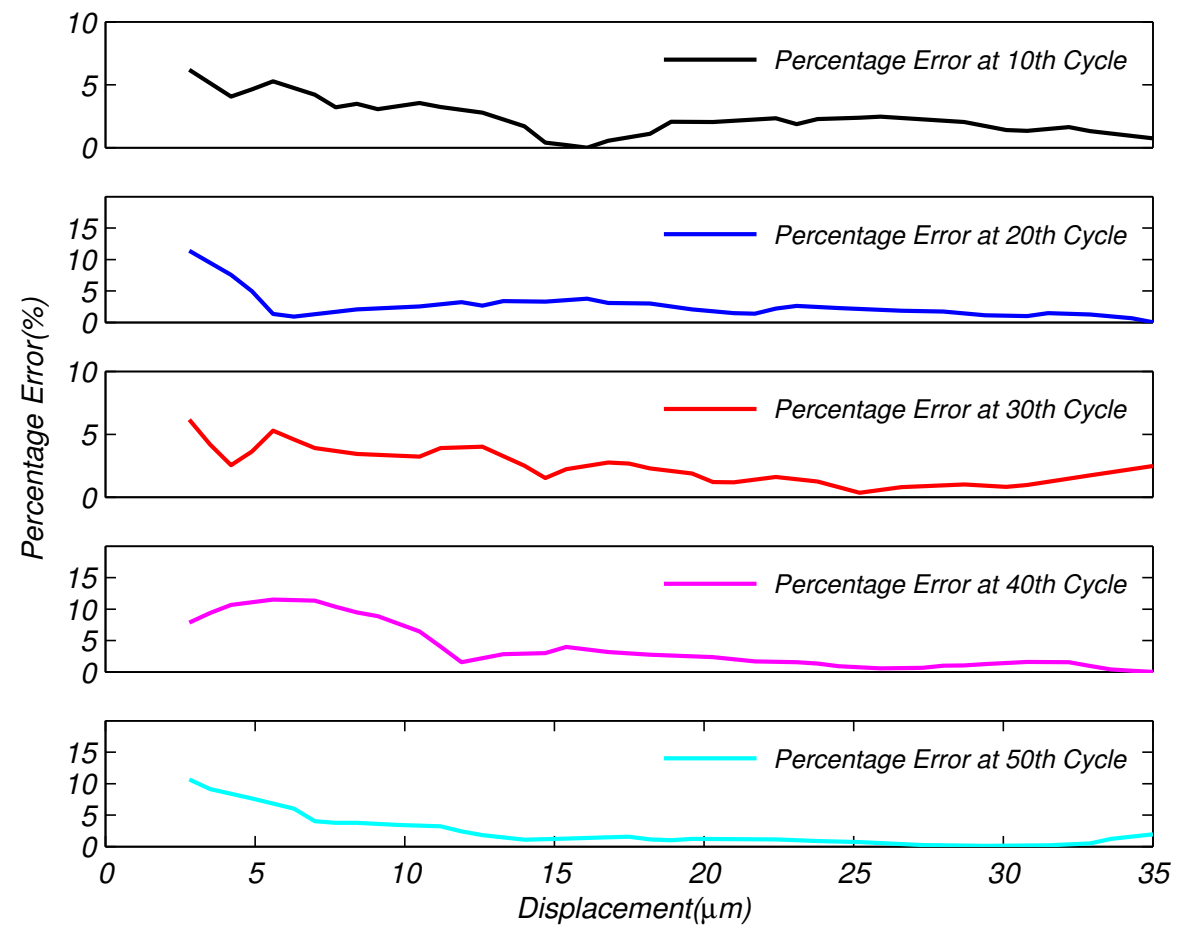

Figure 10: Repeatability test over 50 cycles with seizure points removed 


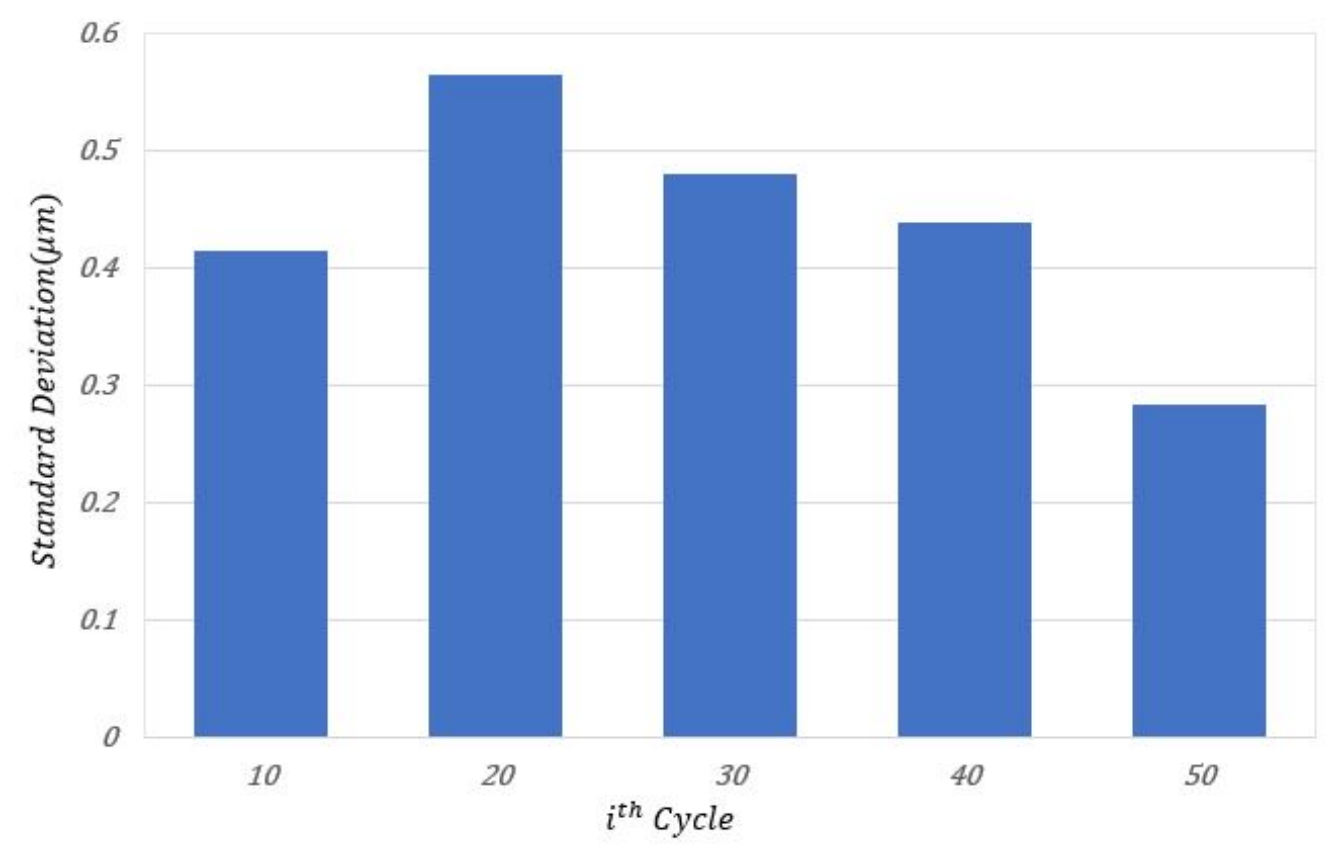

Figure 11: Repeatability Standard Deviation

\subsection{Manufacturing Variability}

As the SAS design requires very precise parts, near the limits of current 3D printing capability, it was important to study the print-to-print variability of the device produced by the 3D printer. Four SASs printed were compared. These devices were printed on the same machine, with the same material in one print batch, but printed independently in the resin bath. Each SAS underwent 50 cycles as was completed in the above repeatability test and their variability was evaluated.

Figure 12 shows the standard deviation of the SAS measurement, compared across four sensors. The results show that three sensors are close in their standard deviation while one is significantly different. This may be attributed to the manufacturing tolerances which are $+-0.05 \mathrm{~mm}$. The pin's nominal diameter is $1.47 \mathrm{~mm}$, if a pin diameter is close to $1.52 \mathrm{~mm}$, it could lead to a tight pin-hole connection with increasing internal friction which makes SAS more likely to experience sticking. If a pin diameter is close to $1.42 \mathrm{~mm}$, a loose pin-hole connection could appear and transfer movement less accurately. However, the overall variability between the four gauges was 

and that large production runs of such gauges would be feasible.

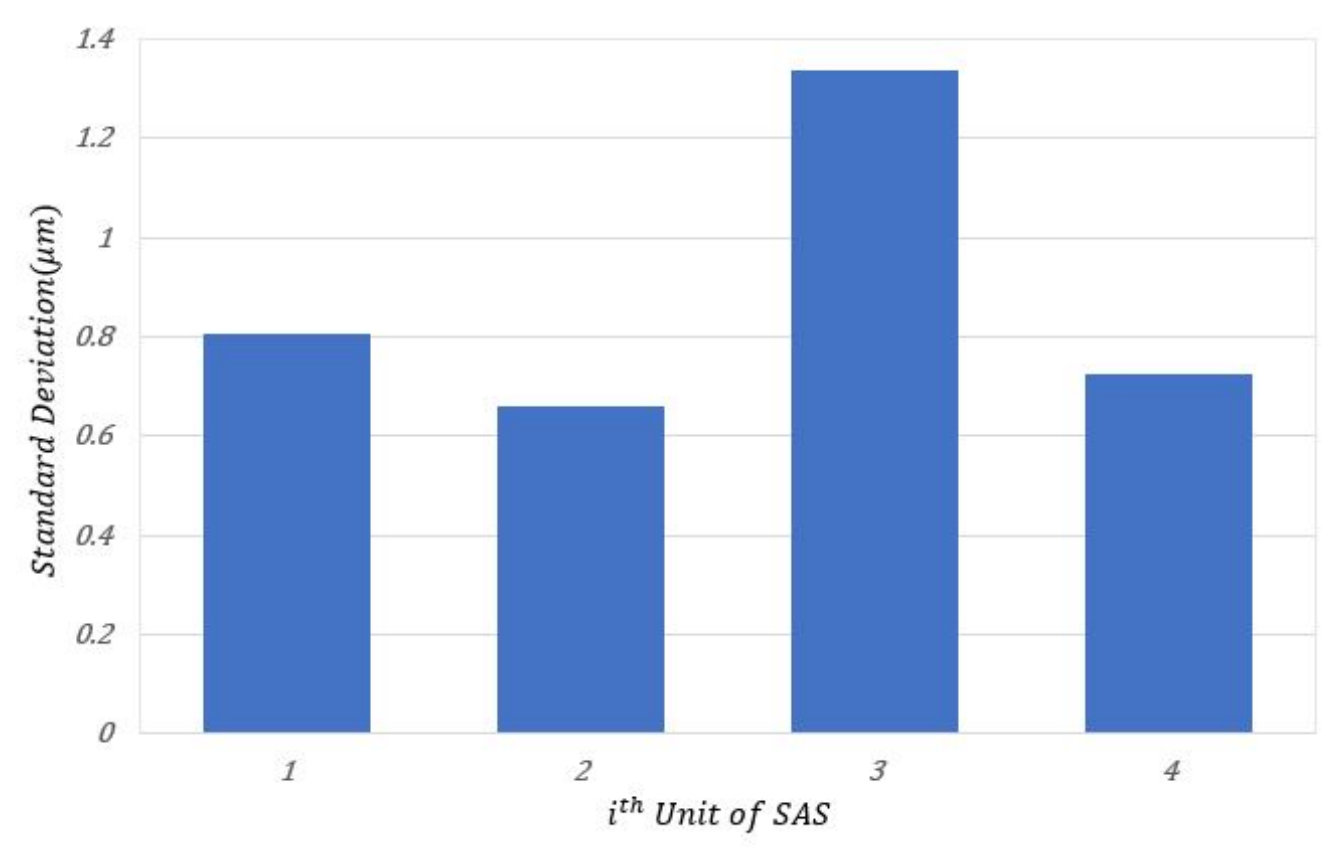

Figure 12: SAS displays small manufacturing variability gauge-to-gauge

small, even with the higher variability on gauge three. This indicate a good degree of repeatability exists with current additive manufacturing techniques,

\subsection{Pull Tester Validation}

The complete SAS assembly was tested on the pull tester in tensile stress to validate the calibration conducted on the piezo motor. SAS measurements were compared to data from two perpendicular strain gauges (for temperature compensation) wired in a 1/4 wheatstone bridge, as shown in Figure 13. A strong agreement between the measurements was observed. The average difference in measurement was $5 \%$.

\section{Weld Trial}

Weld distortion during fabrication processes can result in significant misalignment of shipbuilding assemblies [15]. When upstream residual stresses and deformation cause structural components not to fit at assembly time, 


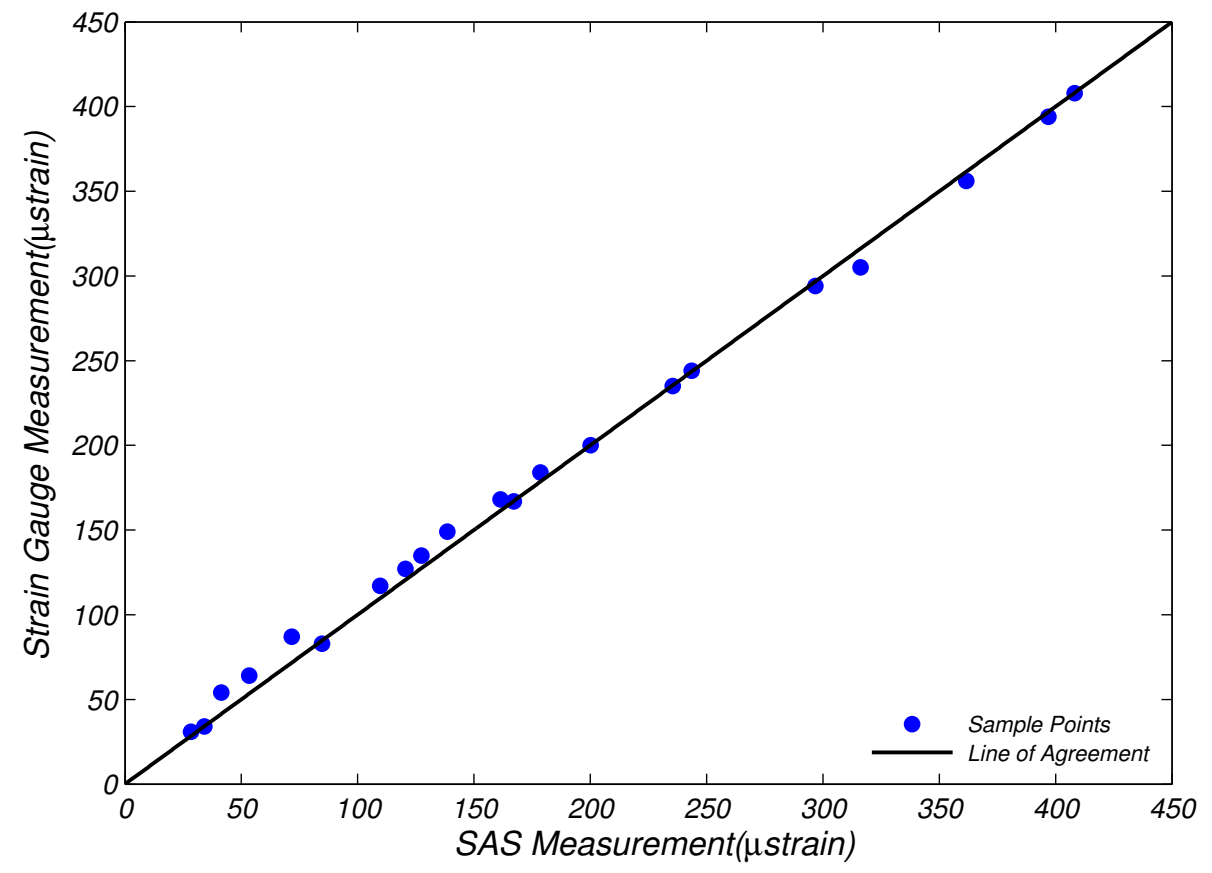

Figure 13: Comparison between SAS and conventional strain gauge on pull tester 
mechanical force as well as thermal heating are used to re-align the structure. This process is time consuming, can damage the structure if done too aggressively, and often damages machinery and equipment pre-outfitted to the structure. Past work has shown that such errors at assembly or grand block integration results in significant cost during shipbuilding [16]. An inexpensive strain sensing technique such as SAS could give fabricators real-time visual feedback to the residual stress state in the structure. This information can translate to procedural changes and quality control checks that reduce the likelihood of misalignment and the resulting rework from weld deformation. To explore the suitability for using SAS during welding for real-time strain measurements, a weld trial was conducted. Given the small size of laboratory specimen compared to a large ship or bridge structure, this work focused on transient thermal stresses from the welding process. Such stresses can reach similar magnitudes in small and large structures, where more complex residual stresses often need large structures with high degrees of restraint to develop.

Two 1/4 inch thick, 12 inch across square low carbon steel plates were butt tig welded together with a single pass. The SAS' sensor arm's was centered in the plate parallel to the weld. To help reduce the heat transferred to SAS during the weld process, given its proximity to the weld (6 inches), a copper bar was fixed beneath the plate and adjacent to the weld location. Additionally, a second piece of steel was clamped to the plate to form a barrier to prevent any weld spatter from striking the SAS and to block the light of the welding process so that the SAS movement could be captured by video camera. This barrier steel was not welded. Figure 14 shows the installation setup.

SAS reacted in real time during the welding process and cool down. Figure 15 shows a time lapse of the movement while the weld bead was being laid and thereafter. During welding, the assembly compressed along the weld axis and SAS' measurement corresponded. SAS responded smoothly to the transient thermal stresses being generated, providing clear visual feedback to the welder and observers of the current state of the material. After the weld was completed, the camera was kept on while the material started to cool down. During cooling, the material's internal compression decreased, and the SAS measured the reduction of stress. SAS followed the entire strain change process and made it visibly observable. This trial demonstrated the practicality of a low-cost strain sensing system. Using only 3D-printed plastic parts and magnetic attachment, it was possible to make thermal welding strains 


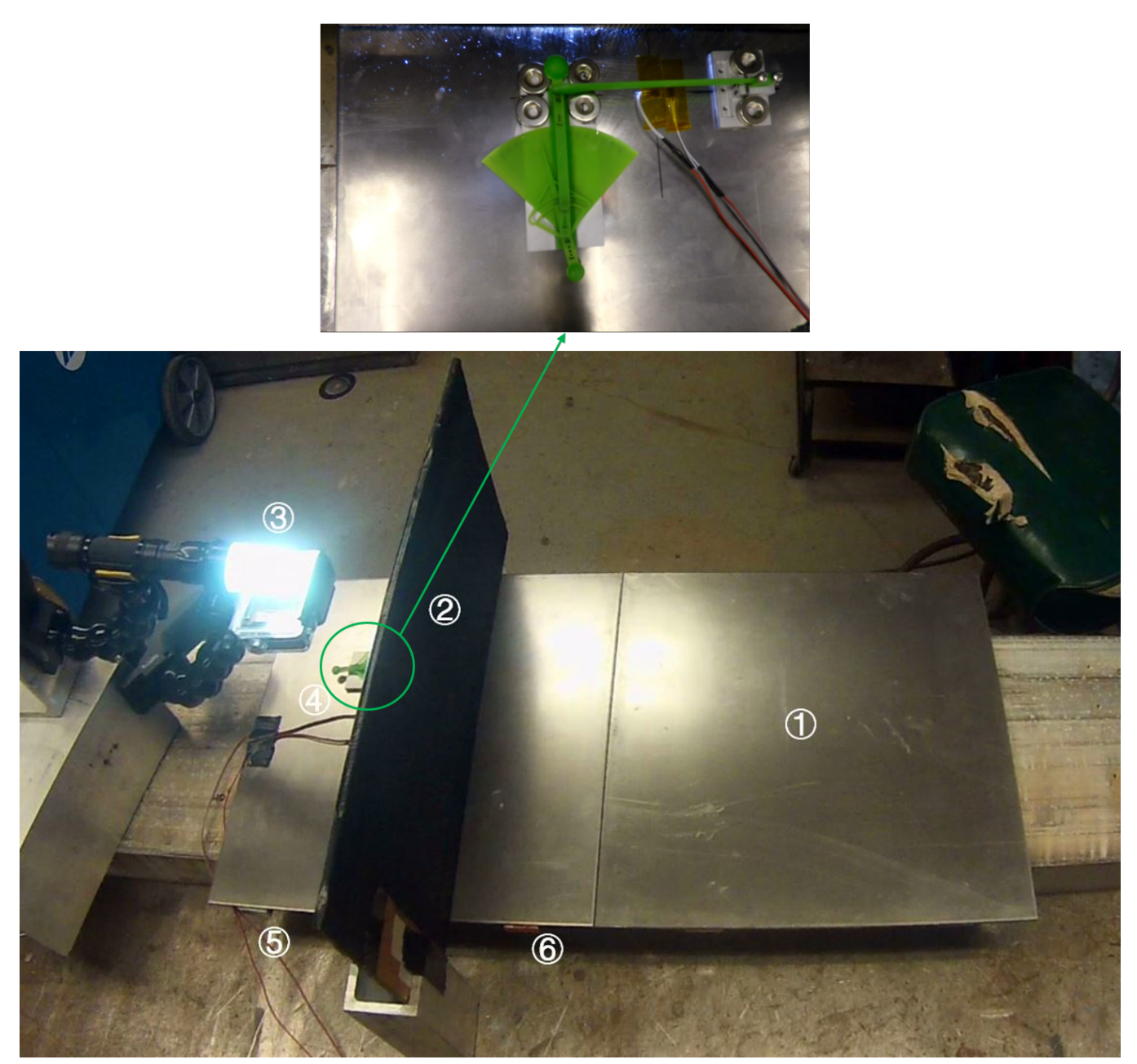

Figure 14: Welding preparation (1) Steel Plate (2) Protection Wall (3) Light and Camera (4) SAS (5) Aluminum Bar (6) Copper Bar) 
visible to the welder and any inspectors examining the work piece. The ease of installation and low cost nature of the gauge could allow structural strain sensing in a variety of fabrication and incident response setting.

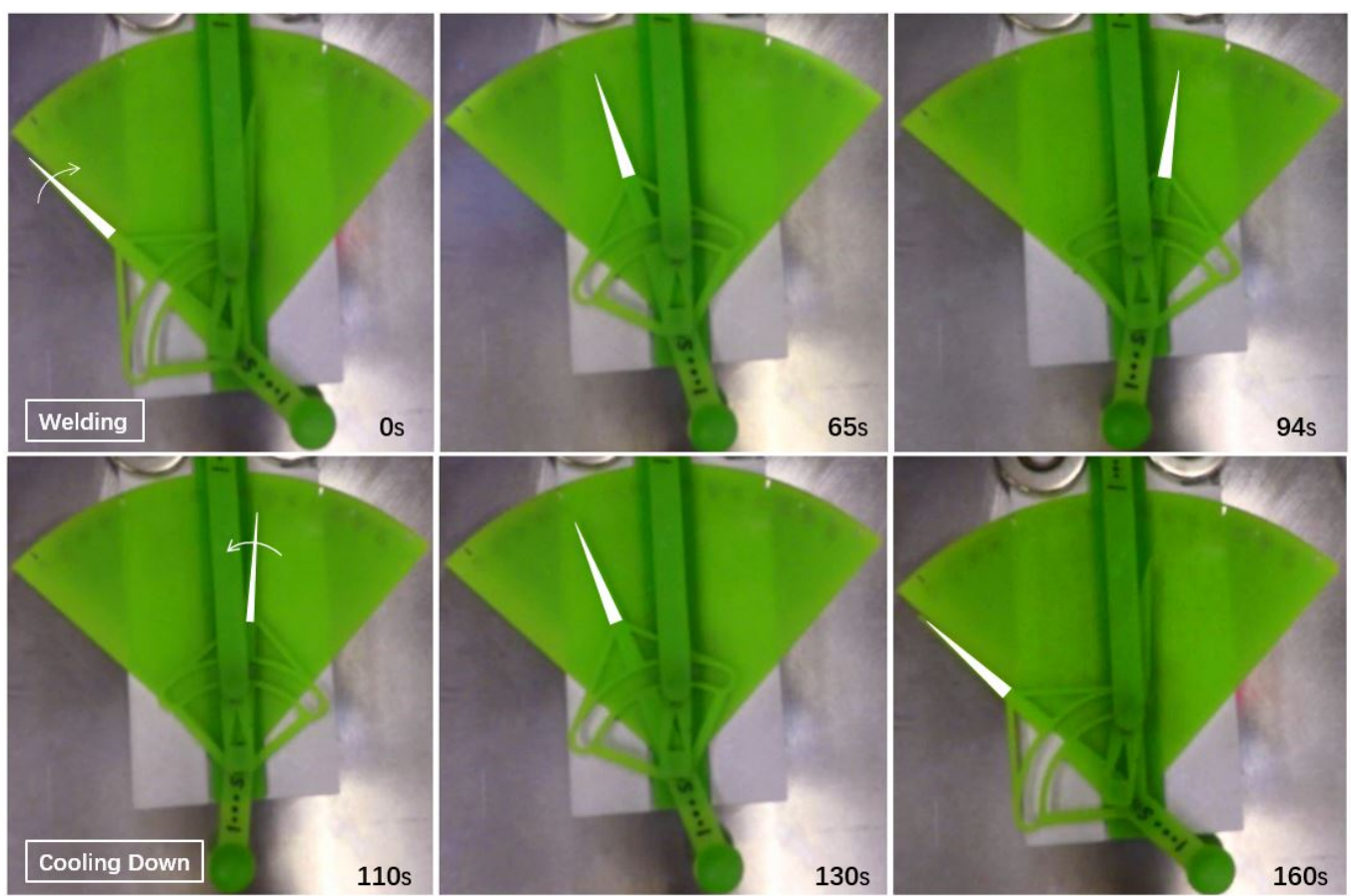

Figure 15: SAS movement during welding test (the first row indicates pointer was moving clockwise and steel was compressing during welding; the second row shows pointer was moving back counterclockwise which means steel was tensing during the cool down process.

\section{Conclusion}

A 3-D printable strain gauge was proposed as a new tool to allow in situ strain monitoring when rapid installation time, low cost, and direct human readability are important characteristics. Using a mechanical advantage approach, the gauge magnifies the change in length between two measuring bases. This strain is then visually displayed on a large gauge with a needle. The principle challenge in constructing such a gauge is minimizing the internal friction from the moving parts given the current accuracy of additive manufacturing, especially for hole and slot construction. 
A series of prototypes were tested to evaluate the accuracy, repeatability, and durability of the gauge. Overall, the gauge was shown to be sensitive and accurate, with a resolution on the order of a single microstrain. The primary problem encountered was temporary sticking of the gauge from internal friction. This occurred in approximately $5 \%$ of the measuring points. There was some gauge-to-gauge variability in the consistency of the measurement, with three of the four tested gauges agreeing well, and one gauge with a larger variability. Over 50 strain cycles no significant degradation of the gauge was experienced, indeed, it appeared that the gauges may be improving after a "break-in" period, though this finding has not been validated by tear-down and inspection of the gauge geometry. Finally, the gauge was shown to be able to capture the build up and release of transient thermal stresses present during a TIG butt weld, displaying these stresses in real-time to the welder.

Overall, this initial work validated the concept of using additive manufacturing to achieve low-cost strain sensing for short-term strain monitoring projects. While such a gauge in no way competes with conventional monitoring techniques for long-term time-history monitoring, for rapid applications during construction and incident response it is now practical to provide realtime strain feedback. Further print material-specific properties need to be examined, including the effect of temperature changes on the gauge, and the impact of humidity and water on the smoothness of the mechanism. Additionally, approaches to mechanically record the maximum value of strain experience would also allow the gauge to be left unattended for short periods of time.

\section{Acknowledgments}

The authors would like to acknowledge Allison Ward and Jiaxi Chen for their help with prototype CAD and 3D printing. The authors would like to acknowledge the support of Dr. Paul Hess of the Office of Naval Research Code 331 under Grant N00014-13-1-0525, the support of the University of Michigan Center for Entrepreneurship via internal funding and the NSF i-CORE program, and the support of the Regents of the University of Michigan.

\section{References}

[1] Kenneth Lim, Leslie Wong, Wing Kong Chiu, and Jayantha Kodikara. Distributed fiber optic sensors for monitoring pressure and stiffness 
changes in out-of-round pipes. Structural Control and Health Monitoring, 23(2):303-314, February 2016.

[2] S. Laflamme, M. Kollosche, J. J. Connor, and G. Kofod. Soft capacitive sensor for structural health monitoring of large-scale systems. Structural Control and Health Monitoring, 19(1):70-81, February 2012.

[3] Ole J. D Kristensen and Forskningscenter Riso. Fundamentals for remote structural health monitoring of wind turbine blades - a preproject, annex E: full-scale test of wind turbine blade, using sensors and NDT. Riso National Laboratory, Roskilde, 2002.

[4] TingHua Yi, HongNan Li, and Ming Gu. Full-scale measurements of dynamic response of suspension bridge subjected to environmental loads using GPS technology. Science China Technological Sciences, 53(2):469479, February 2010.

[5] M.B. Kane, C. Peckens, and J.P. Lynch. Design and selection of wireless structural monitoring systems for civil infrastructures. In Sensor Technologies for Civil Infrastructures, pages 446-479. Elsevier, 2014.

[6] Haksoo Choi, Sukwon Choi, and Hojung Cha. Structural Health Monitoring system based on strain gauge enabled wireless sensor nodes. pages 211-214. IEEE, June 2008.

[7] J.J. McCullagh, T. Galchev, R.L. Peterson, R. Gordenker, Y. Zhang, J. Lynch, and K. Najafi. Long-term testing of a vibration harvesting system for the structural health monitoring of bridges. Sensors and Actuators A: Physical, 217:139-150, September 2014.

[8] Nephi R. Johnson, Jerome P. Lynch, and Matthew D. Collette. Response and fatigue assessment of high speed aluminium hulls using shortterm wireless hull monitoring. Structure and Infrastructure Engineering, $0(0): 1-18,2017$.

[9] St350 Strain Transducer. http://bditest.com/product/sensors/ strain-sensors/bdi-strain-transducers/. Accessed: 2017-11-13.

[10] David Bak. Rapid prototyping or rapid production? 3d printing processes move industry towards the latter. Assembly Automation, 23(4):340-345, December 2003. 
[11] Robert Bogue. 3d printing: the dawn of a new era in manufacturing? Assembly Automation, 33(4):307-311, September 2013.

[12] Yusuf Yagci, Steffen Jockusch, and Nicholas J. Turro. Photoinitiated Polymerization: Advances, Challenges, and Opportunities. Macromolecules, 43(15):6245-6260, August 2010.

[13] Ferry P.W. Melchels, Jan Feijen, and Dirk W. Grijpma. A review on stereolithography and its applications in biomedical engineering. Biomaterials, 31(24):6121-6130, August 2010.

[14] Amit Joe Lopes, Eric MacDonald, and Ryan B. Wicker. Integrating stereolithography and direct print technologies for $3 \mathrm{~d}$ structural electronics fabrication. Rapid Prototyping Journal, 18(2):129-143, March 2012 .

[15] N.R. Mandal and P. Biswas. A review on development of weld induced distortion analysis. volume 2, pages 901-908, Lisbon, 2011. CRC press.

[16] T. D. Huang, Michael Harbison, Lee Kvidahl, David Niolet, John Walks, J. P. Christein, Mark Smitherman, Mark Phillippi, Pingsha Dong, Larry DeCan, Vince Caccese, Paul Blomquist, David Kihl, Rick Wong, Matthew Sinfield, Natale Nappi, James Gardner, Catherine Wong, Michael Bjornson, and Allen Manuel. Reduction of Overwelding and Distortion for Naval Surface Combatants. Part 2: Weld Sizing Effects on Shear and Fatigue Performance. Journal of Ship Production and Design, 32(1):21-36, February 2016. 